Żanna Fiodorenko-Dumas

ORIGINAL PAPER

Agnieszka Kurkowska

Małgorzata Paprocka-Borowicz

\title{
SPINE PAIN IN THE FIREFIGHTER PROFESSION
}

Wroclaw Medical University, Wrocław, Poland

Department of Physiotherapy

\begin{abstract}
Background: Musculoskeletal disorders mainly affecting the spine constitute one of the major social problems. Frequently, they constitute the cause of prolonged absence at work. Working in a fire brigade is specific because of the physical strain, working time under adverse conditions or stress related to rescue operations. Material and Methods: The study group comprised 61 firefighters, 60 men $(98.36 \%)$ and 1 woman (1.64\%). The age of examined firefighters ranged 20-56 years old. The average age of the examined persons was 33.77 years old and the average working service in a fire brigade was 9.59 years. The following research instruments were applied as the study methods: own survey, the Numerical Rating Scale, the International Physical Activity Questionnaire (IPAQ) - long version and the Oswestry Disability Index (ODI) questionnaire. The Pearson correlation coefficient at significance level of $\mathrm{p}<0.05$ was used for determining the dependencies among the variables. Results: Knowledge of ergonomic lifting and handling principles concerning heavy loads was reported by $84 \%$ of the group, the remaining $16 \%$ declared ignorance of such rules. The dependence of pain on the length of service of the examined was insignificant and amounted to 0.281 Pearson's $r$. The results of the ODI questionnaire did not significantly change statistically with age. Conclusions: The IPAQ confirmed the high level of physical activity of the study population. Even though the study group was small, the results of ODI showed a minor degree of disability. Med Pr 2018;69(4):365-373
\end{abstract}

Key words: disability, pain, firefighters, load, spinal, ergonomics of work

Corresponding author: Żanna Fiodorenko-Dumas, Wroclaw Medical University, Department of Physiotherapy, Grunwaldzka 2, 50-355 Wrocław, Poland, e-mail: z.fiodorenko@poczta.onet.pl

Received: August 9, 2017, accepted: December 29, 2017

\section{INTRODUCTION}

Nowadays, spinal pain constitutes a problem of an increasingly wider community and has become a civilization disease. Spine pain relates to the cervical, thoracic and lumbosacral sections. There is no clear reason for the occurrence of pain. The primary sources prove that there are numerous factors which may cause spinal pain acting individually or overlapping one another. Pain mostly occurs in the cervical and lumbar sections. This is associated with their higher degree of mobility as well as the function of lifting the weight of the head - in case of the cervical section as well as the whole body by the lumbar section of the spine. These 2 opposite functions performed simultaneously are ensured thanks to the specific structure of the vertebrae which forms the column of the spine [1].

A rational mechanical load on the spine has a positive influence on its bone structure, intervertebral discs as well as surrounding tendons and muscles. Physical effort and spine strain increase the strength of these structures, thus they become more resistant to damage [2]. However, in order to strengthen the spine and its stabilizing tissues in this manner, it is necessary to apply the principles of ergonomics during the day activities. Improper technique of their performance may easily lead to injuries, deterioration of tissues and development of bad movement habits.

For healthy persons, a constant postural muscles tension is responsible for stabilization of the torso during all activities. They require a relevant strength and endurance for a proper muscle work. In the case of occurrence of spinal pain, reduced statistical strength of postural muscle is usually observed. It has been assumed that the endurance level of these muscles is at an appropriate level until pain in a particular section occurs. Reduction of muscle endurance is associated with their quicker tiring. This in turn, weakens the control of movements and muscles work in less ergonomic patterns, and their energy expenditure increases significantly [3]. In addition to the increased efficiency of movement, spinal pain occurs over time and consequently limitation of spine mobility. This makes it somewhat difficult to perform certain activities, especially in the profession of a firefighter. Musculofascial disorders that are manifested in pain are the most com- 
mon functional dysfunctions of soft tissues. They usually disappear within a few weeks without any medical intervention but they may also last much longer. The disappearance of pain does not mean that the problem has been remedied. If the cause of pain is not eliminated, it will most likely recur [4].

Working in the firefighting service is associated with a high health hazard. It is impossible to remove difficult working conditions, thus firefighters have to adapt to such conditions to some extent. Physical and mental fitness, resistance to stress and general health is required from the rescuers.

Studies by Damrongsak et al. [5] analyzed the influence of various factors stimulating the occurrence of spinal pain in a group of firefighters. Demographic variables such as age, medical history concerning spinal pain, body mass index (BMI) and waist circumference were taken into account. Other factors were work-related stress and obeying the ergonomic principles of work as well as physical activity aimed at preventing pain. The collected information enabled to find back pain in $30 \%$ of the subjects. The conducted studies allowed the most common factors to be identified and these were work-related stress or earlier incidents related to spine injuries. The BMI proved to be significant in the study group. Damrongsak et al. [5] observed the need to extend the studies to other professions such as nurses and police officers.

A firefighter is exposed to great physical and mental effort as well as numerous harmful factors in their work environment. Therefore, extinguishing fire is frequently associated with rescuers' life and health hazards [6].

The factors that should be mentioned include: radiation, smoke, toxic gases or mechanical interaction with fragments of objects in the case of abrasions and strokes. Due to so many factors, firefighters have difficulties in certain cases to determine the situation and the exact time they can spend in an adverse environment. It is further impeded by the fact that during rescue and firefighting operations, all the components that must be taken into consideration by the firefighter dynamically change. Equipment protecting respiratory tracts is essential in fighting internal fires as well as external fires accompanied by a hot microclimate. In such cases, the protective equipment contains a breathing apparatus weighing up to $17 \mathrm{~kg}$ as well as a facial mask which are attached to the firefighter's body with belts and harness. Due to such heavy weight, the distance between the layers of the rescuer's clothing is reduced at the fixing points, which lowers the protective efficiency of the suit. It is also easier to get burnt in these places because warm clothing directly adheres to body. Combat clothing protects firefighters against thermal skin injuries. According to standards, protective clothing cannot weigh more than $3.8 \mathrm{~kg}$. The weight is so big that it induces visibly increased parameters, such as: heart rate, lung minute ventilation, oxygen consumption per kilogram of body weight and also respiratory frequency. These parameters increase much more in the protective suit than in a usual sport uniform [7].

Studies by Nuwayhid et al. [8] assessed the influence of professional activity on the occurrence of the initial pain in the lower spine depending on the performed activities. Firefighters served the basis for the analysis, and their activities were divided into high and low risk of the occurrence of spinal pain. The highest rates of the risk of the occurrence of pain were related to climbing, cutting structures and lifting heavy objects.

It should not be forgotten that protective clothing with additional personal equipment weighs about $15-20 \mathrm{~kg}$, air cylinder $-7 \mathrm{~kg}$ and breathing apparatus $-4 \mathrm{~kg}$. Hoses used by firefighters, depending on the type, weigh about $5-10 \mathrm{~kg}$, however, in addition to this weight, a firefighter must also withstand the backwash power of water. A single part of a sectional ladder weighs $12 \mathrm{~kg}$ and the entire ladder of this type consists of 4 sections. The weight of some equipment carried by firefighters (e.g., a motor pump or power generator) is about $200 \mathrm{~kg}$. Rescue and firefighting equipment is often transported in unfavorable conditions, such as roofs, hills, wet soil, ladders. Moreover, operation of this equipment also requires an additional effort. The time of being present in such unfriendly conditions depends on the time of the rescue operations. Extinguishing a small fire usually takes about $1 \mathrm{~h}$, an average - about 3-4 h, and a large fire - even several hours. In the case of forest or peat fire, firefighting even may last for a few days [8].

Work related to the firefighter profession causes a lot of various pains not only in the back but also in other parts of the body. Such studies were conducted by Gentzler et al. [9]. They evaluated 2 professional groups of firefighters and paramedics. For the first professional group the activities with a high risk of the occurrence of discomfort included lifting a firehose (while extinguishing fires) and rolling the firehose on the ground. For the group of paramedics it was lifting life-saving equipment and patient medical care which require different positions of the body. The authors of this article indicate the need to use technical solutions and to 
modify the execution of the current tasks into a more ergonomic and pain-reducing manner.

Katsavouni et al. [10], on the other hand, assessed the influence of professional work on the burnout and stress related to traumatic events which frequently occur in the work of a firefighter. The assessment was carried out with the use of standardized tools and a questionnaire prepared by the authors. The study group consisting of over 3000 firefighters was impressive and enabled to reach objective conclusions. The most traumatic events for the study group included death during an intervention, saving children and responsibility for the victims of the event.

Therefore, the principles of work ergonomics change, adjusting them to the changing conditions of firefighting operations, and they cannot always be fully fulfilled. Taking into consideration the weight that is carried by the whole locomotor system, and especially the spine, this occupational group is particularly vulnerable to pain in this section of the body. Additional psychological stress related to a rescue operation as well as the events occurring after the incidents significantly influence both the psychological and physical condition of this professional group.

\section{Purpose}

The purpose of this paper has been to evaluate the influence of the length of the firefighting service on the occurrence of spinal pain. Moreover, attempts were made to find the relationship between the occurrence of spinal pain and the age of examined persons, their physical activity and applied principles of work ergonomics.

\section{MATERIAL AND METHODS}

The Bioethics Committee at the Medical University in Wrocław granted a consent number KB - 279/2017 to carry out the study.

Criteria for inclusion in the study:

working in the firefighting service for at least one year, a patient's consent to participate in the study.

Criteria for exclusion from the study:

vertebral fracture,

other mechanical spine injuries,

cancer or infection of spine or prevertebral muscles, neurological disease that may cause spinal pain.

The tested group consisted of 61 firefighters. Most of persons subject to study were male $(98.36 \%)$ and only one woman was examined (1.64\%).
The age of examined firefighters ranged $20-56$ years old. The average age of the examined persons was 33.77 years old. The shortest length of service in firefighting, that is a year, was reported by $6 \%$ of examined. The longest recorded length of service is 31 years. The average of all reported values concerning the length of service in firefighting is 9.59 years.

Moreover, a half of firefighters has never been working in any other place, $26 \%$ had an extra physical and mental work, $12 \%$ in their second job was sitting most of the time and $8 \%$ of the examined had additional physical work with heavy loads.

In order to evaluate the influence of the length of service in firefighting on the occurrence of spinal pain and in order to find the dependency between the occurrence of spinal pain and the age of the examined, their physical activity and applied principles of work ergonomics, the following research instruments were applied: own survey, the Numerical Rating Scale (NRS), the International Physical Activity Questionnaire long version and the Oswestry Disability Index (ODI) questionnaire.

The own survey consisted of 23 questions. Its initial part allowed to collect sociodemographic information about the group. Further questions in the own survey concerned pain suffered by firefighters, preventive measures and knowledge of applying the principles of ergonomic sitting, standing, lifting and handling objects.

The Numerical Rating Scale is an 11-point scale used for numerical determination of pain intensity. It includes numbers from 0 to 10 . The respondents were asked to mark the intensity of pain on particular scales on the day of examination, when it usually occurs and on the day of the worst pain. The respondents were informed that 0 means no pain and 10 - the worst possible pain.

The International Physical Activity Questionnaire (IPAQ) is divided into 5 parts. The initial 4 concerns physical activity at work, when moving, at housework and during free time. The last part evaluates the time spent sitting. A long version of IPAQ allows for an accurate calculation of time spent on the above-specified activities. Based on the collected data, the level of physical activity for the time spent at work and leisure time was calculated, expressed in metabolic equivalent (MET) unit, where 1 MET means the consumption of oxygen while sitting and is equal to $3.5 \mathrm{ml} \mathrm{O} / 2 \mathrm{~kg}$ b.w. $/ \mathrm{min}$.

The last research instrument was the Oswestry Low Back Pain Disability Questionnaire. It is designed to evaluate the degree of disability caused by pain in the lumbar section of the spine. It consists of 10 questions 
regarding as follows: the intensity of pain, care, lifting objects, walking, sitting, standing, sleeping, social life, traveling and change in pain intensity. Each answer was assigned a score between $0-5$. The highest score that could be obtained in the survey was 50 points. The lower score of the respondent, the less significant was his/her disability.

\section{Statistical analysis}

In order to verify the research questions, the study group was subject to statistical analyses, taking into account its differentiation. They were performed with the use of 2 statistical programs: Statistica 13 and IBM SPSS Statistics 24. The Pearson correlation coefficient at significance level of $\mathrm{p}<0.05$ was used to determine the dependencies between the variables. The results were presented in the form of graphs or descriptive statistics, taking into account: the mean, median, modal, minimum, maximum, standard deviation and variation.

\section{RESULTS}

The Pearson coefficient was used for the calculation of the relation between the length of service in firefighting and the frequency of occurrence of spinal pain. The study had 59 degrees of freedom. The Pearson coefficient is 0.281 and is greater than 0.25 , which means that the results are statistically significant at 0.043 . The obtained value of the Pearson coefficient indicates on a weak correlation, as shown in the Table 1.

The analysis of correlation of the age of respondents with a point and ODI percentage share with the use of the Pearson coefficient showed no correlation between the variables (Table 1).

When observing the results concerning the correlation between the body mass index (BMI) and the results of ODI, it is plausible to say that there is a positive correlation between the variables. It is obvious that body weight may increase the experienced spinal pain (Table 1).

Before starting the service in firefighting, spinal pain occurred in $38 \%$ of firefighters, and $62 \%$ of employees had never noticed such symptoms before. As many as $64 \%$ of respondents reported an increase of the frequency of spine pain occurrence after starting work in the firefighting service. According to $18 \%$ of respondents, the incidence of spinal pain did not change after starting work as a firefighter. Three percent of firefighters noticed less back pain since they work in the firefighting service, and in $15 \%$ such pain has never occurred. Most responses, as much as $71 \%$ concerned lumbosacral section of spine. The cervical spine section was indicated in $19 \%$ of answers, and the thoracic section as well as iliac joints were $5 \%$.

The most common pain-inducing activities reported by the respondents include overload ( $40 \%$ of answers) and longer remaining in one position (36\%).

In the case of an ergonomic lifting and handling loads, the persons who know these principles constituted $84 \%$ of the group, the remaining $16 \%$ declared ignorance of such rules. Among the persons familiar with a correct lifting and handling methods, only $88 \%$ of firefighters applied such methods. The correlation of the Pearson coefficient was calculated to determine the influence of applying the principles of ergonomic standing, sitting and lifting heavy objects on the incidence of spine pain. Its value amounted to 0.26 and it indicated a low correlation. However, the influence of applying these principles on the ODI was 0.35 , which was indicating a moderate correlation. The statistical significance in this case is at the level of $\mathrm{p}<0.01$. This is shown in the Table 1 .

The greatest number of firefighters - $29 \%$ were assessing the occurring pain as 5 in the visual analogue scale (VAS), and the only slightly lower number - $25 \%$ were assessing the pain as 4 . The value of 3 was marked by $13 \%$ of respondents, $15 \%$ marked 2 and $2 \%$ marked 1 . Higher points in the scale, such as 6,7 and 8 were marked by $8 \%, 2 \%$ and $6 \%$ of respondents, respectively (Table 2).

Table 1. Correlations between selected variables, back pain and Oswestry Disability Index (ODI) results in the study group of firefighters $(\mathrm{N}=61)$

\begin{tabular}{lll}
\hline \multicolumn{1}{c}{ Variable } & Frequency of pain & ODI \\
\hline Length of service & & \\
$\mathrm{p}$ & $0.281^{*}$ & $0.215^{*}$ \\
$\mathrm{r}$ & 0.043 & 0.048 \\
Age & & \\
$\mathrm{p}$ & $0.344^{*}$ & 0.161 \\
$\mathrm{r}$ & 0.016 & 0.108 \\
Body mass index (BMI) & & \\
$\mathrm{p}$ & $0.324^{*}$ & $0.361^{* *}$ \\
$\mathrm{r}$ & 0.010 & 0.008 \\
Application of principles & & \\
of ergonomic standing, & & \\
sitting and lifting heavy & & \\
objects & & $0.351^{* *}$ \\
$\mathrm{p}$ & $0.263^{*}$ & 0.003 \\
$\mathrm{r}$ & 0.020 & \\
\hline
\end{tabular}

* Significant correlation at the level of 0.05 .

${ }^{* *}$ Significant correlation at the level of 0.01 . 
Table 2. Descriptive values of pain in the Visual Analog Scale (VAS)

\begin{tabular}{lccccccc}
\hline \multicolumn{1}{c}{ Pain } & M & Me & Modal & Min. & Max & SD & Variance \\
\hline On the examination day & 1.56 & 0 & 0 & 0 & 6 & 2.03 & 4.13 \\
Usually occurring & 4.23 & 4 & 5 & 1 & 8 & 1.62 \\
The strongest & 6.60 & 7 & 8 & 2 & 9 & 1.92 \\
\hline
\end{tabular}

$\mathrm{M}$ - mean, $\mathrm{Me}$ - median, min. - minimal value, $\max$ - maximal value, $\mathrm{SD}$ - standard deviation.

Table 3. Level of physical activity of examined firefighters during work and leisure time based on International Physical Activity Questionnaire (IPAQ)

\begin{tabular}{lcccrrrr}
\hline $\begin{array}{c}\text { Physical activity } \\
\text { [MET-min/week] }\end{array}$ & M & Me & Modal & Min. & Max & SD & Variance \\
\hline Work & 5527 & 5130 & 3474 & 746 & 11790 & 3214 \\
Leisure time & 4235 & 3588 & 1752 & 0 & 11730 & 329941 \\
Total & 9762 & 9660 & multiple & 1756 & 23418 & 4989 & 9421436 \\
\hline
\end{tabular}

Abbreviations as in Table 2.

Table 4. The Pearson correlation coefficient for the influence of physical activity during particular parts of the week on the incidence of spinal pain and Oswestry Disability Index (ODI) in the study group of firefighters $(\mathrm{N}=61)$

\begin{tabular}{lcc}
\hline \multicolumn{1}{r}{ Physical activity } & Frequency of pain & ODI \\
\hline Activity during the day & & \\
r & 0.090 & 0.073 \\
p & 0.244 & 0.289 \\
Activity at work & & \\
r & 0.021 & -0.033 \\
p & 0.437 & 0.401 \\
Activity in leisure time & & \\
r & 0.125 & 0.153 \\
p & 0.168 & 0.120 \\
\hline
\end{tabular}

The physical effort calculated based on the IPAQ of the firefighters during work was the average of $5527 \mathrm{MET}$-min/week, the most commonly calculated level of activity was $3474 \mathrm{MET}-\mathrm{min} /$ week. The lowest value calculated in the group of firefighters subject to the study was $746 \mathrm{MET}-\mathrm{min} /$ week and the greatest is $11790 \mathrm{MET}-\mathrm{min} /$ week. During the free time, all the aforementioned values were slightly lower. On average, the physical activity of respondents in their free time was $4235 \mathrm{MET}$-min/week. The most common value was 1752 MET-min/week. The lowest level of physical activity was found in $2 \%$ of respondents and it was the lack of any activity during leisure time - 0 MET-min/ week, while the highest value was 11730 MET-min/week. After summing up the values of levels of physical activity at work and during the leisure time, the weekly level of physical activity was obtained. On average, it was $9762 \mathrm{MET}-\mathrm{min} / \mathrm{week}$, with the lowest value of 1756 MET-min/week which was at the level of sufficient physical effort and the highest value of 23418 MET-min/ week, which meant high physical effort, as shown in the Table 3.

The results of the IPAQ showed a high level of physical activity in the study group. Therefore, the influence of daily activity on the incidence of spinal pain and the results of ODI were analyzed (Table 4). Although it was not possible to determine statistical significance between the variables, the results of ODI were in reverse correlation with the incidence of spinal pain (Table 4).

The average score of ODI was 6.84. The most common point indicators were 1 , and it was also their lowest value. In turn, the highest point value was 25 . In the case of ODI expressed in terms of percentage, their average value oscillates within the range $13.67 \%$ (Table 5).

Table 5. Descriptive values of Oswestry Disability Index (ODI)

\begin{tabular}{lcccccrr}
\hline & ODI & M & Me & Modal & Min. & Max & SD \\
\hline Total & 6.84 & 6 & 1 & 1 & 25 & 5.03 \\
ODI [\%] & 13.67 & 12 & 2 & 2 & 50 & 10.05 \\
\hline
\end{tabular}

Abbreviations as in Table 2. 


\section{DISCUSSION}

Firefighters belong to the professional group that is most vulnerable to musculoskeletal disorders. Due to the nature of work, especially in rescue and firefighting units, the work of a firefighter is associated with a high risk to health. Therefore, the employees of the firefighting service are required to keep very good physical and mental condition. The weight of equipment used during rescue and firefighting operations makes it difficult for firefighters to move, and they often have to reach hardto-access places, climb a ladder, roofs or move between rooms destroyed by fire. Such situations force the need to lift and carry loads in positions unfavorable to the spine. The firefighters are also exposed to high psychological stress because of a frequent threat to their lives and colleagues as well as responsibility for rescued people. Another burden having a negative impact on the health of firefighters is shift work, thus they have to be alert for $24 \mathrm{~h}$ of their work. For the entire time they have to be ready to react and respond to the call. Due to such difficult working conditions, firefighters have been qualified for earlier retirement.

Szuber and Sobala [11] carried out studies in which they determined the most common reasons for leaving work by the firefighters. Over 4 years, $14.2 \%$ of respondents within the group subject to the study resigned from their job as firefighters. The most of them - 40\% retired, while $38 \%$ received sick leave, $15 \%$ left on their own request and the remaining group (7\%) resigned for other reasons. The frequency of leaving work by firefighters subject to the study of Szubert and Sobala increases with their age. Termination of the employment by the employees under the age of 30 usually refers to resignation at their own request. The firefighters above the age of 30 retire or obtain a sick leave, while the employees who resign from their job above the age of 45-49 years old are most often forced to obtain a sick leave. The same dependency is visible between the length of service in firefighting and the coefficient of leaving the service. The employees having a shorter working experience submit termination of the employment at the request. The firefighters who have worked in this profession for more than 15-19 years usually retire or receive a sick leave $[11,12]$.

Szubert and Sobala [12] identified the most common reasons for leaving the firefighting service: in the case of obtaining a sick leave, retiring and leaving at own request. The firefighters leave the job due to sick leave because of cardiovascular diseases $-26 \%$ of the respondents. Almost as often, that is in $25 \%$ of cases, the reason for a sick leave are diseases of the musculoskeletal system. Sixteen percent of firefighters obtain a sick leave because of mental disorders, the remaining part because of neurological diseases - $13 \%$, respiratory system diseases $-6 \%$ and digestive system diseases $-5 \%$ of cases. The reasons for the retirement of firefighters are most often diseases of the musculoskeletal system as well as neurological diseases. Firefighters who, during the study carried out by Szuber and Sobala, received a disability certificate, obtained it mostly due to musculoskeletal diseases $-56 \%$ of cases. Other common reasons are mental disorders $-51 \%$, cardiovascular diseases $-38 \%$ and other diseases suffered by firefighters [12].

It results from own studies that before staring work in firefighting, $38 \%$ suffered from spinal pain. On the day of examination, as many as $85 \%$ of the respondents reported such problems, and according to $64 \%$ of the respondents, the pain is a greater nuisance since they started to work as firefighters. Based on this data, it is plausible to state that working in the firefighting service negatively affects the condition of the spine. In order to make a better assessment in this respect, analyses of correlation of the degree and frequency of pain occurrence with the length of service in firefighting and the age of firefighters were carried out. It results from theses analyses that longer service as a firefighter is associated with more frequent and severe pain. However, a relatively low value of the Pearson coefficient indicates weak correlation and thus, this result should be regarded as a tip only. A significant correlation was observed in the study group between the results of ODI and the working time as well as the BMI of the respondents (Table 1). Macfarlane et al. [13] found similar conclusions in the studies concerning the impact of the performance of physical work on the occurrence of pain in the lumbar section of the spine. According to these studies, pain in this area is suffered more often by persons whose work requires them to lift, pull or push objects heavier than $25 \mathrm{lb}(11.34 \mathrm{~kg})$ as well as when work requires to stand or walk for a longer time. This dependency is visible among the respondents of both sexes, however it occurs to a greater extent in the case of women. It means that the nature of the work performed by the respondent affects the occurrence of the spinal pain. In the same group of respondents, there was no dependency between the length of service and the occurrence of the spinal pain [13]. According to Cichońska studies, the nature of work affects the pain in the 
lumbar section of the spine. It has been observed that the physical workers suffer the spinal pain the most [14].

In turn, a moderate level of correlation between the age and pain suffered by firefighters has been observed in own studies. Older respondents more often struggle with pain than their younger colleagues. On this basis, it is plausible to state that the age has a greater impact on the occurrence of the spinal pain than the service in firefighting. However, the lack of the relation between the frequency of pain occurrence and age of the respondents was shown in the studies of Depa and Drużbicki [15].

The most frequent localization of pain suffered by firefighters is, according to own studies, the lumbar-sacral section of the spine. It is exposed to high loads related to work performed. The second, in terms of incidence, reported pain occurs in the cervical section of the spine but it is much less frequent. Depa and Drużbicki [15] observed that men who performed physical work suffered pain in the lumbar section more often than in the case of other types of work [15].

Own studies showed that a high level of physical activity of firefighters did not affect the occurrence of the spinal pain. Such result may be due to a high level of physical activity of each of the respondents and its low differentiation among the examined group (Table 3). Similar results were found by Ridan et al. [16] in the studies concerning the spinal pain suffered by active volleyball female players. Their physical activity was also high and did not affect the degree of pain [16].

Depa and Drużbicki [15] concluded from their studies that the manner of the performance of tasks at work as well as observance of the preventive measures for spinal pain was of greater importance than the type of the work performed with regard to the occurrence of spinal pain. This is consistent with the results of own studies which have shown that applying the principles of ergonomic standing, sitting and lifting heavy objects reduces the incidence of spinal pain and its intensification. The studies of Lisiński and Samborski [17] carried out within a group of physiotherapists showed a correlation between the occurrence of the lumbar section of spine and lifting heavy objects, prolonged standing and remaining in one position. The persons who were often exposed to such factors at work had greater problems with the spinal pain [17].

Szuber and Sobala [11,12] observed a high level of incapacity to perform work in the case of some firefighters. According to their studies, 2/3 of the retiring respondents were sick and their health condition constitutes almost invalidity. According to their observations, firefighters in poor health condition prefer to withstand pain for several years, so after reaching 15 years of service they can retire [12]. It results from own observations that in the group of firefighters subject to the study were $2-3 \%$ of persons with a severe disability and $3-15 \%$ with mild (moderate) disability.

Cichon [18] noted that other factors than the degree of tissue damage also affect the degree of pain suffered. These factors are strictly related to the psychological impact: cognitive and emotional. An individual, emotional reaction of a human being has a great influence on feeling pain. Treatment of pain in people unstable emotionally is difficult because the mental state, which also determines the method of pain treatment, is constantly changing. The pain described by a patient was rarely relevant for the changes observed in his/her tissues. This is because everyone feels pain in his/her own manner and it is also determined by psychological factors. Cichon [18] also found that the patients who suffered depression in the past are generally less resistant to pain [18]. Similar conclusions are presented by Walden-Gałuszko [19]. She also notes that the impact of emotions on the pain that is felt is higher in the sad, depressed or frightened persons [19].

Sowizdraniuk [20] in his paper found a significant impact of stressors related to the profession of a firefighter on the readiness to carry out rescue and firefighting operations. He noted that a good mental condition of firefighters was responsible for a proper performance and performance at work. Sowizdraniuk [20] mention as the most frequent traumatic events in the work of firefighters:

events in which there are fatalities,

situations in which health and life of colleagues is threatened,

presence of children among the victims,

harm to their own or colleagues,

death of a rescuer, a firefighter.

Sowizdraniuk distinguishes in his paper 2 types of stress - eustress (motivating) and distress (negative). Distress arises when the stressor affects a person for too long or too intensively. When this type of stress affects a firefighter, his/her health condition gradually deteriorates, which hampers his/her functioning at work and daily life. In the case of such persons, irritability, depression, difficulties in making decisions are observed very often - which greatly hampers rescue operations, as well as numerous other symptoms. A bad decision made by one firefighter may negatively affect the en- 
tire rescue team and make it difficult to carry out the rescue and firefighting actions. Therefore, the mental condition of firefighters should be kept on a relevant level. One of the reasons of a high chronic stress level is the constant readiness and waiting for a call, as well as the uncertainty about the situation that they will face in a given day. Research shows that as many as $86 \%$ of firefighters experienced a traumatic event at least once during their service [20].

In the study of Kaflik-Pieróg and Ogińska-Bulik [21], the level of stress experienced by firefighters was higher than in other occupational groups. The stressogenic factor within the examined group was a high sense of responsibility and risk of loss of health and life. In the group subject to the study, despite the high level of stress of the respondents, no significant, negative psychological effects were observed. This is the most probably due to the fact that the firefighters feel the highest level of stress during rescue operations, and then the stress is gradually reduced. In turn, the studies of Mackałło and Borzęcki [22,23] showed that a longer service in firefighting was associated with a higher level of psychological stress together with all its effects. The dependency of pain intensity and emotional condition has been proved also in numerous other studies [22,23].

Extensive studies concerning back pain based on the literature review appeared in the Medycyna Pracy journal [24]. It concerned farmers but it indicated the scale of the problem which concerned various professions. The studies performed by Bovenzi [25] in 1986-97 showed that there was a growing tendency in back pain, which may have resulted from the unnatural torso movement and sometimes from lifting heavy objects. Studies by Park et al. [26] also confirmed the occurrence of spinal pain among the study population. The researchers observed a positive correlation with the profession and age of the respondents. Further studies by Holmberg et al. [27] evaluated the impact of workload on the occurrence of musculoskeletal system disorders. Lower back pain was dominant as compared to shoulder or elbow pain. Studies by Rosecrane et al. [28] concerned the factors related to back pain. It was most often farm work, which eliminated 1 out of 5 respondents in this profession. Sprince et al. [29] showed that people with lower education and aged over 45 complained about spinal pain most often. Meyer [30], apart from the standard factors such as age or BMI, assessed the influence of stress on spinal pain. His studies confirmed that it was one of the factors that determined the occurrence of pain.
After reviewing available studies, it resulted that the problem of spinal pain among firefighters was serious. It is a result of overlapping of many factors, not only mechanical but also psychological, cognitive and emotional ones. This indicates the need of applying a holistic approach to the problem. It would be useful to carry out more extensive studies evaluating all these aspects. It would allow for a more detailed determination of the causes of spinal pain among firefighters and their early incapacity to work.

\section{CONCLUSIONS}

1. The International Physical Activity Questionnaire (IPAQ) is the main objective tool for evaluating physical activity; however, it has proven not to be entirely accurate for the studied group of firefighters due to the active nature of work of the respondents.

2. The IPAQ has confirmed the high lev-el of physical activity of the study population.

3. Even though the study group was small, the results of ODI showed a minor degree of disability.

4. Due to the relatively small study group, it may only be indicated that there is the need to perform studies on a larger study population.

\section{REFERENCES}

1. Gregory DS, Seto CK, Wortley GC, Shugart ChM. Acute lumbar disk pain: Navigating, evaluation and treatment choices. Am Fam Physician. 2008;78(7):835-42.

2. Arnoldi CC. Intravertebral pressures in patients with lumbar pain. A preliminary communication. Acta Orthop Scand. 1972;43(2):109-17, https://doi.org/10.3109/17453677208 991249.

3. Szostak L, Marcinkowski JT. [Functional pain ailments of spine as a serious problem of public health. Part 3. Compression mobilizations as a research and therapeutic tool in functional thoracic spine pain symptoms]. Probl Hig Epidemiol. 2012;4(93):679-81. Polish.

4. Chochowska M, Wytrążek M, Marcinkowski JT, Huber J. [Myofascial pain syndrome - Etiology, pathogenesis, symptomatology]. Fizjoterapia. 2012;20(2):89-96. Polish.

5. Damrongsak M, Prapanjaroensin A, Brown K. Predictors of back pain in firefighters. Workplace Health Saf. 2018; 66(2):61-9, https://doi.org/10.1177/2165079917709020.

6. Verna J, Stowell C, Parker R, Duran A, Mayer J. [Firefighters \& back injuries: The new study]. Fire Rescue Mag. 2010;4:11. 
7. Węsierski T, Kowalczyk P. [Physiological impact on firefighters wearing special garments during operations]. Bezpiecz Tech Pożarnicza. 2015;38(2):63-72. Polish.

8. Nuwayhid IA, Stewart W, Johnson JV. Work activities and the onset of first-time low back pain among New York City firefighters. Am J Epidemiol. 1993;137(5):539-48, https:// doi.org/10.1093/oxfordjournals.aje.a116707.

9. Gentzler M, Stader S. Posture stress on firefighters and emergency medical technicians (EMTs) associated with repetitive reaching, bending, lifting, and pulling tasks. Work. 2010;37(3):227-39.

10. Katsavouni F, Bebetsos E, Malliou P, Beneka A. The relationship between burnout, PTSD symptoms and injuries in firefighters. Occup Med (Lond). 2016;66(1):32-7, https:// doi.org/10.1093/occmed/kqv144.

11. Szubert Z, Sobala W. [Temporary work disability among firemen employed in rescue and fire brigades]. Med Pr. 2000;51(5):415-23. Polish.

12. Szubert Z, Sobala W. [Health reasons for firefighters to leave their job]. Med Pr. 2002;53(4):291-8. Polish.

13. Macfarlane GJ, Thomas E, Papageorgiou AC, Croft PR, Jayson MIV, Silman A. Employment and physical work activities as predictors of future low back pain. Spine. 1997; 22(10):1143-9, https://doi.org/10.1097/00007632-1997051 50-00015.

14. Cichońska M, Maciąg D, Machała E. [The severity of pain and ways to cope with pain by people with discopathy]. Pol J Health Fitness. 2015;1:83-98. Polish.

15. Depa A, Drużbicki M. [Assessment of frequency of lumbalgia occurrence with relation to the character of performed work]. Przegl Med Uniwer Rzesz. 2008;1:34-41. Polish.

16. Ridan T, Guzy G, Niziołek K, Dubaj W, Hładki W. [Characteristics of the non-specific low back pain incidence in a group of active female volleyball players]. Ostry Dyżur. 2014;7(3):79-85. Polish.

17. Lisiński P, Samborski W. [Low back pain among physiotherapeutic]. Bal Pol. 2006;3:156-60. Polish.

18. Cichon P. [Psychological aspects of pain]. Terapia i Zdrowie. 2016;1(12):11-4. Polish.

19. Walden-Gałuszko K. [Psychological aspects of pain and treatment]. Med Paliat Prakt. 2007;1(2):66-70. Polish.
20. Sowizdraniuk P. [Stress factors At work rescuer]. Zesz Nauk Państw Wyższ Szk Zawod Witelona Legn. 2013;9:83-8. Polish.

21. Kaflik-Pieróg M, Ogińska-Bulik N. [Occupational stress, self-efficacy belief and burnout syndrome in fire-fighters]. Acta Univ Lodziens Folia Psych. 2003;7:37-47. Polish.

22. Mockałło Z. [Chronic stress in firefighting - A review of research]. Bezpiecz Pr. 2009;9:20-3. Polish.

23. Borzęcki M, Kamiński B. [Treatment of chronic pain]. Terapia i Leki. 1979;7(29):14-21. Polish.

24. Solecki L. [Complaints of low back pain among private farmers exposed to whole body vibration: A literature review]. Med Pr. 2014;65(1):55-64. Polish, https://doi. org/10.13075/mp.5893.2014.002.

25. Bovenzi M, Betta A. Low-back disorders in agricultural tractor drivers exposed to whole-body vibration and postural stress. Appl Ergon. 1994;25(4):231-41, https://doi.org/ 10.1016/0003-6870(94)90004-3.

26. Park H, Sprince NL, Whitten PS, Burmeister LF, Zwerling C. Risk factors for back pain among male farmers: Analysis of Iowa Farm Family Health and Hazard Surveillance Study. Am J Ind Med. 2001;40(6):646-54, https://doi.org/10.1002/ ajim.10025.

27. Holmberg S, Thelin A, Stiernstrom E, Svardsudd K. [The impact of physical work exposure on musculoskeletal symptoms among farmers and rural non-farmers]. Ann Agric Environ Med. 2003:10(2):179-84.

28. Rosecrance J, Rodgers G, Merlino L. Low back pain and musculoskeletal symptoms among Kansas farmers. Am J Ind Med. 2006;49(7):547-56, https://doi.org/10.1002/ ajim.20324.

29. Sprince N, Park H, Zwerling C, Whitten P, Lynch C, Burmeister L. Risk factors for low back injury among farmers in Iowa: A case-control study nested in the agricultural health study. J Occup Environ Hyg. 2007;4(1):10-6, https:// doi.org/10.1080/15459620601067266.

30. Meyer JP, Flenghi D, Deschamps JP. Effects of manual handling, posture, and whole body vibrations on low-back pain. Int J Occup Saf Ergon. 1998;4(4):449-70, https://doi. org/10.1080/10803548.1998.11076404.

This work is available in Open Access model and licensed under a Creative Commons Attribution-NonCommercial 3.0 Poland License - http://creativecommons.org/licenses/by-nc/3.0/pl/deed.en. 